\title{
Some Features of Boundary Layers and Transition to Turbulent Flow
}

\author{
ARNOLD M. KUETHE* \\ University of Michigan
}

\begin{abstract}
Summary
A brief review of the status of knowledge of laminar and turbulent boundary layers and of transition is given. Some new experimental results on transition in Poiseuille flow in a tube arc reported. One set shows transition excited by the annular wake behind a ring airfoil. Another shows oscillograms of velocity fluctuations in the flow for several imposed disturbance amplitudes. These demonstrate successive stages in the breakdown of the flow.
\end{abstract}

\section{(1) INTRODUCTION}

$\mathrm{T}$ HE RAPIDLY EXPANDING literature on boundary layers reflects the fact that there is a practical interest in an ever-widening range of Reynolds Numbers and in higher and higher Mach Numbers. The low Reynolds Numbers associated with hypersonic flight and the development of means of delaying transition have focused much effort on laminar boundary layers and on the mechanism of transition. Also, the drive toward a real understanding of the turbulent processes in shear flows, as well as toward the gathering of practical information on shearing stresses and interactions, has gained momentum with the refinement of experimental equipment and methods.

The space available here permits only a brief review of some aspects of boundary layers. Some of the topics are treated quite briefly, while others, notably heat transfer and the characteristics of turbulence in shear flows, have been omitted. These omissions are treated elsewhere in this issue in papers by Rannie on heat transfer and by Lin on turbulence.

More complete accounts of some of the topics and background material are given in references 1 and 2 . Reference 3 describes briefly some recent investigations. A forthcoming volume of contributed papers on "Fifty Years of Boundary Layer Theory" was not available at the time the present account was written.

\section{(2) Laminar Boundary Layer}

Over the past decade particularly, theories of the laminar boundary layer have been extended into the hypersonic range of speeds, into the low density or slip flow regime, and into temperature ranges where gas imperfections must be considered. Shock-wave boundary-layer interaction has been the subject of many investigations. Three-dimensional boundary layers have likewise assumed a great practical importance, because of effect on the performance of axial flow compressors, on the flow over highly swept and low

* Felix Pawlowski Professor of Aerodynamics. aspect ratio wings, and on bodies at angles of attack.

The original works by Busemann ${ }^{4}$ and von Kármán, ${ }^{5}$ on the compressible laminar boundary layer on a flat plate with Prandt1 Number unity and viscosity proportional to a power of the absolute temperature were followed by that by von Kármán and Tsien, ${ }^{6}$ in which heat transfer was taken into account. The most exact analysis to date on the flat plate is that by $\mathrm{Crocco}^{7}$ for a range of Prandt1 Numbers and several laws of variation of viscosity coefficient with temperature, including that due to Sutherland. An important result of these calculations is the relative insensitivity of the results to the law of variation of viscosity with temperature.

From a practical standpoint, important investigations by Howarth, ${ }^{8}$ Illingworth, ${ }^{9}$ and Stewartson ${ }^{10}$ enable a comparison of compressible velocity profiles with "equivalent" incompressible profiles. Under the assumptions of Prandt1 Number unity, viscosity proportional to absolute temperature, and zero heat transfer, they transformed the compressible boundary-layer equation into a form identical with the incompressible equation. Then, the transformations applied to any solution of the incompressible equation yield the "equivalent" compressible boundary layer. Crocco and Lees ${ }^{11}$ applied the transformation to mixing between two streams with promising results.

The conditions under which similar solutions of the compressible boundary-layer equations ${ }^{12-14}$ exist reveal further properties of the compressible boundary layer. With Prandtl Number unity and viscosity proportional to the absolute temperature, the conditions on the outside flow are derived such that distributions within the boundary layers are similar. By means of these equations, the effect of pressure gradient and heat transfer on skin friction and flow separation can be studied for specified pressure distributions. Solutions are obtained on an analog computer. ${ }^{12}$

Compressible boundary layers in continuous adverse pressure gradients are of practical interest at subsonic speeds, but at supersonic speeds the adverse gradients will, in most instances, take the form of incident shock waves. The details of the flow field in the vicinity of a shock impinging on a surface have been studied in detail by Ackeret, Feldmann, and $\operatorname{Rott}^{15}$ and by Liepmann, Roshko, and Dhawan. ${ }^{16}$ In the latter investigation, the authors found that, if the boundary layer is laminar, the flow separates in a limited region ahead of the impinging wave and the flow field is altered about 50 boundary-layer thicknesses upstream and several hundred thicknesses out from the surface. However, 
in spite of the flow separation and adverse pressure gradient, transition to turbulent flow did not always occur immediately aft of the shock. Donaldson and Lange ${ }^{17}$ found a critical pressure ratio $\Delta p / q_{1}\left(q_{1}\right.$ is the dynamic pressure in the free stream) beyond which the laminar boundary layer separated for free-stream Mach Numbers of 1.6 to 2.05. They found the critical $\Delta p / q_{1}$ to be proportional to $R_{x}^{-1 / 2} \dagger$ The shocks across which $\Delta p / q_{1}$ was measured were formed by a collar on a body of revolution.

Another type of shock-wave boundary-layer interaction occurs near the leading edge of a body in hypersonic flow. ${ }^{18}$ Two influences are responsible for the interaction. First, the inclination of the shock wave is small at high Mach Numbers so it will lie close to the outer edge of the boundary layer, and second, the high temperatures generated by the deceleration in the vicinity of the leading edge cause the boundary layer to be many times thicker than it is at low speeds at the same Reynolds Number. As a result the shock will be detached and the curvature will be high at the apex. This interaction was first recognized by $\operatorname{Tsien}^{19}$ and first investigated by Shen. ${ }^{20}$

A recent paper by Lees ${ }^{21}$ goes into the details of this and subsequent investigations of hypersonic viscous flow. The parameter $M_{\infty} t / c$, where $t$ is the thickness of the airfoil or maximum diameter of a body of revolution and $c$ is the chord of the airfoil or length of the body, is Tsien's similarity parameter for inviscid hypersonic flow. However, for viscous flow, the interaction parameter $\chi=M_{\infty}{ }^{3} \sqrt{C} / \sqrt{R e_{x}}$, where $C=\mu_{w} T_{\infty} \div$ $\mu_{\infty} T_{w}$ (the subscript $w$ referring to conditions at the wall), is found to govern the pressure distribution and the development of the boundary layer near the leading edge of a plate. The pressure is near ambient for low values of $\chi$ (far downstream) and increases linearly to several times ambient for high values of $\chi$ (near the leading edge). The effect of blunting the leading edge is to increase substantially the pressure for small $x$.

Analysis of the eifects of high surface temperatures, such as occur in flight at high Mach Numbers, must include the effects of dissociation of the air and of variable air properties. Moore ${ }^{22}$ has shown, on the basis of solutions on a differential analyzer, that over a wide range of plate temperature and heat transfer the effect of dissociation on the local skin-friction coefficient is negligible.

In flight at very high altitudes, where the mean free path is greater than about 1 per cent of the boundarylayer thickness, slip at the surface is encountered and air can no longer be treated strictly as a continuum. Tsien $^{23}$ defined the slip flow range as occuring when $0.01<M / \sqrt{R e}<0.1$ for $R e>1$. Then the reflection and accomodation coefficients govern the energy and momentum of the reflected molecules, respectively, and hence the skin friction and equilibrium temperature of the surface. Although the trends of the experimental results on drag and heat-transfer coefficients

$\dagger$ Shock-wave interaction with turbulent boundary layers will be discussed in Section IV. follow theoretical predictions, ${ }^{24}$ important discrepancies may be ascribed to shock-wave boundary-layer interactions near the leading edge and uncertainties in the values of the reflection and accomodation coefficients.

The investigation of three-dimensional boundary layers was greatly facilitated by the independent observations of Prandt1, ${ }^{25}$ Sears, ${ }^{26}$ and Jones ${ }^{27}$ that the equations of motion for incompressible viscous flow past a yawed cylinder are separable. As a result, the components of the flow in the plane normal to the generators of the cylinder are independent of the angle of yaw-i.e., of the spanwise velocity component. This "independence principle" requires, however, that spanwise derivatives of all flow properties be zero. Therefore, transition to turbulence (see Section 3) as well as the development of the wake after laminar separation might be expected to be influenced by the yaw angle.

Simple methods of calculation are worked out by Rott and Crabtree, ${ }^{28}$ and Crabtree $^{29}$ has given an approximate method for calculating compressible flow over a yawed cylinder, based on the IllingworthStewartson transformation. For supersonic flow past a yawed cone, Moore ${ }^{30}$ and Hayes ${ }^{31}$ showed that velocity and density in the boundary layer are constant along parabolas with vertices at the vertex of the cone and lying in a meridional plane. Moore analyzed the flow in the plane of symmetry for supersonic flow over a cone at high angles of attack. Differences in the behavior of the boundary-layer equations over different ranges of angle of attack were interpreted as indicating changes in the character of the flow over the lee sidei.e., boundary-layer flow at low angles of attack is supplanted by symmetrically placed vortices, and finally by the von Kármán vortex street at high angles of attack. Allen and Perkins ${ }^{32}$ analyzed roughly the secondary flow over a cylindrical body and identified the drag due to the cross-flow component as an increment to the lift. They found excellent agreement with experiment. Mager $^{33}$ derived momentum equations applicable to three-dimensional flows including effects of rotation.

\section{(3) Transition to Turbulent Flow}

The stability of laminar flow, whether it be in a boundary layer, in a fully developed flow in a tube or channel, or in a jet or wake, is susceptible to analysis as a linear problem. A recent monograph by $\mathrm{Lin}^{34}$ summarizes the state of the knowledge and shows that much is known about the stability of the basic flow to infinitesimal disturbances. However, the establishment of turbulent flow as a consequence of flow instability is far from well understood. The experiments of Schubauer and Skramstad ${ }^{35}$ describe in detail the in stability of the laminar boundary layer on a flat plate, but only very recently has it been possible to delineate some of the details of the changeover from regular to turbulent fluctuations. Some of these experiments will be described later. A study of transiton at supersonic speeds has recently been carried out by Probstein and $\operatorname{Lin} .^{36}$ 
There appears to be no single sequence of events that describes the transition phenomena under all circumstances. The initial disturbances may be two- or three-dimensional; they may be excited by turbulence, ${ }^{35}$ by surface roughness, ${ }^{37}$ by disturbances imposed within the boundary layer, or by shock waves. ${ }^{17}$ Whatever their source, however, the rate of amplification, and therefore the rapidity with which transition follows the disturbance, will be affected by pressure gradient, ${ }^{35}$ Reynolds Number, ${ }^{35}$ Mach Number, ${ }^{38,}{ }^{39}$ suction, ${ }^{40}$ heat transfer, ${ }^{41}$ and curvature of the streamlines. ${ }^{42-45}$

If the initial disturbances are small, their subsequent growth or decay follows the linearized theory initially. If the disturbance grows, its rate of growth determines at what stage of its development the nonlinear terms, which were neglected in the analysis, take over and govern the transition process. If, on the other hand, the initial disturbance is large enough, the process may be nonlinear from the start.

Transition in three-dimensional boundary layers introduces some new aspects tending in general to move the transition upstream. A theoretical and experimental investigation by Gregory, Stuart, and Walker ${ }^{45}$ was initiated after observations on swept wings showed transition occuring upstream of its position on unswept wings. The theoretical study concerned the stability of flow in the boundary layer on a rotating disc; this flow was chosen because it represents a relatively simple three-dimensional solution of the Navier-Stokes equa$\operatorname{tion}^{46}$ and it shows some similarity with the boundary layer on a swept wing. The stability analysis showed a disturbance which may be described roughly as a superposition of Tollmien-Schlichting waves on TaylorGoertler vortices. ${ }^{42}$ The Taylor-Goertler vortices occur in a boundary layer over a concave surface and are known to exert a powerful influence on transition. Hence, their appearance in a three-dimensional boundary layer probably accounts for the earlier transition due to sweep. Experiments with china clay on the surface of a sweptback wing show streaks roughly parallel to the streamlines near the surface. The presence of these streaks is interpreted as indicating the presence of the Taylor-Goertler vortices, since their axes lie along the streamlines. Experiments at supersonic speeds ${ }^{47}$ show qualitatively the same effect of sweep on transition-i.e., the transition point moves upstream with increasing sweep.

Present knowledge of the detailed nature of transition consists to a large extent of isolated observations on a small number of configurations. Visual studies of the life history of particular disturbance configurations such as horseshoe vortices ${ }^{48,49}$ give a qualitative idea of a mechanism by which energy can be transferred from the main flow into fluctuations. However, it does not appear possible to describe by means of a single mechanism all of the phenomena associated with transition-e.g., the sudden changes that occur at the transition front.
These sudden changes are described phenomenologically by Emmons ${ }^{50}$ postulate that transition comes about through the random appearance of "turbulent spots" and their subsequent growth. The rate of growth of the spots as observed on the surface of water in a shallow channel was found to check roughly with the measurements of Charters ${ }^{51}$ on transverse contamination. By postulating that the spots appear in a random fashion in time and space and that a fully developed turbulent boundary layer exists within the spot, Emmons could match the observed dependence between average skin friction and Reynolds Number through the transition region.

The upstream location of the transition front would, according to Emmons' postulate, wander in a random fashion with time. The random wandering of the transition front at supersonic speeds has been observed by Evvard, Tucker and Burgess ${ }^{52}$ by means of schlieren pictures of conical flow, and by Schubauer and Klebanofi ${ }^{53}$ by means of hot-wire measurements of the intermittency factor on a flat plate at low speeds. The separate spots have been observed in schlieren photographs of supersonic flow as a laminar region sandwiched between two turbulent regions.

Schubauer and Klebanoff measured the details of the growth of the spots. They conclude, in agreement with Emmons, that transition occurs naturally as a succession of turbulent spots which grow more or less independently as they move downstream, finally merging into a turbulent boundary layer. $\dagger$

Some measurements made recently by R. J. Leite ${ }^{54}$ under the author's supervision add some information on the details of transition.t The measurements were made with a hot-wire anemometer in fully developed laminar flow in a circular tube 1.25 in. in diameter and $73 \mathrm{ft}$. (700 diameters) long. Air was discharged from a high-pressure source through baffles, screens, and a settling chamber, thence through the tube. About 68 ft. (650 diameters) from the entrance a disturbance generator, consisting of a loud speaker coil with axis parallel to the flow, was connected with an axially symmetric member inside the tube. The member inside the tube was oscillated axially at frequencies up to 100 cycles per sec. Reynolds Numbers $U_{\max } a / \nu$, where $a$ is a radius of the tube, varied from 4,000 to 13,000 .

The interesting feature of this flow lies in the theoretical prediction that it is stable to all infinitesimal axially symmetric disturbances at all Reynolds Numbers. ${ }^{55}$ Other flows, such as boundary layers or flow in twodimensional channels, show complete stability only at Reynolds Numbers below some critical value. Against the theoretical prediction of the stability of tube flow is the practical fact that the flow does become turbulent when sufficiently disturbed.

$\uparrow$ Further discussion of reference 53 will be found in the paper by C. C. Lin entitled Aspects of the Problem of Turbulent Motion in this issue, p. 453.

$¥$ The investigation was supported by the USAF Office of Scientific Research. 


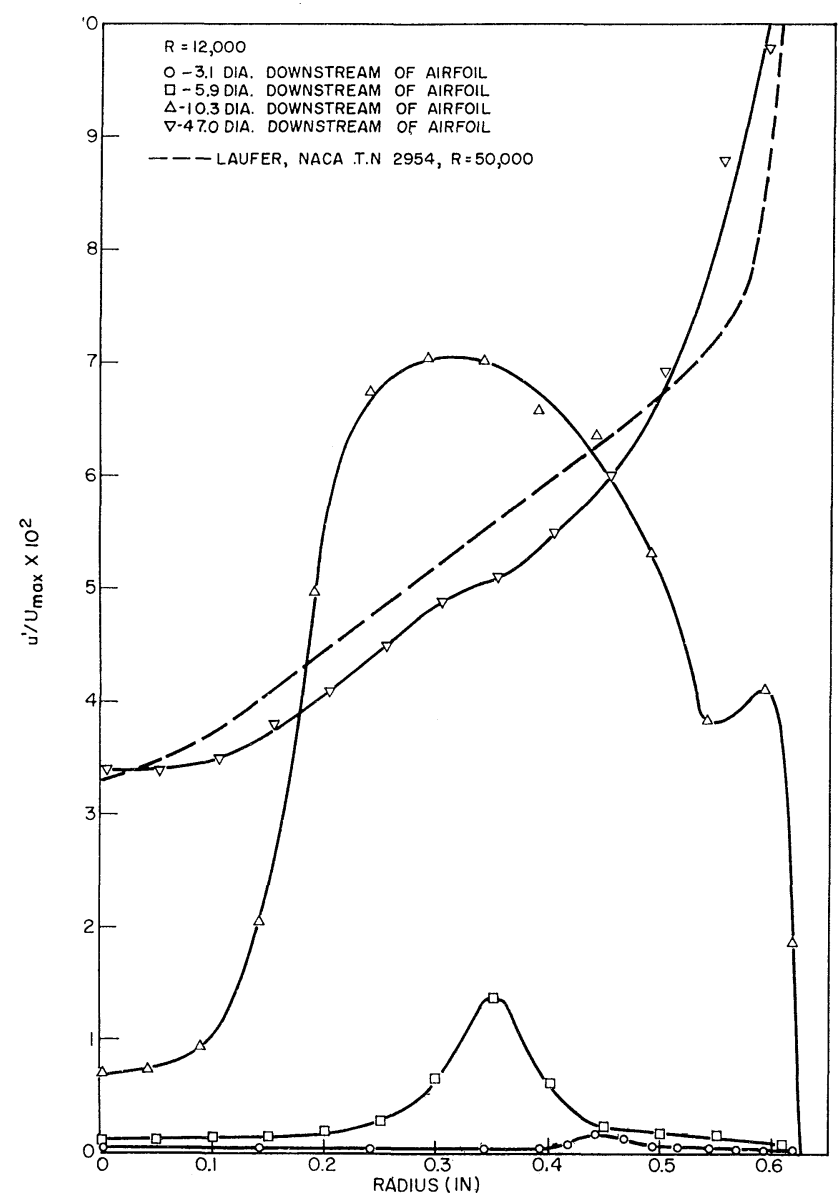

FIG. 1. Radial distribution of turbulence in wake of ring airfoil of radius 0.45 in.

Leite's measurements show that the flow is indeed stable up to the maximum Reynolds Number attainable in the tests $(13,000)$ as long as the magnitude of the disturbance does not exceed a critical value, which depends on Reynolds Number. The measurements and their comparison with theory will be reported in detail elsewhere. Our concern here will be only with a few observations applicable to the study of transition.

The measurements which led to the conclusion that the flow is stable to small amplitude disturbances were made downstream of an oscillating sleeve 0.002 in. thick and 2 in. long, fitting closely to the inner wall of the tube. The measurements described here involved a larger amplitude disturbance, generated by a $0.9 \mathrm{in}$. diameter ring airfoil of about 0.1 in. chord, 0.003 in. thick, set at an angle of attack of about $6^{\circ}$. The ring was symmetrically placed inside the tube and was oscillated by means of an oscillator connected to the loud speaker coil.

Hot-wire measurements of the relative mean velocity $U / U_{\max }$ and relative root mean square fluctuation $u^{\prime} / U_{\max }$ at a Reynolds Number of 12,000 are shown in Figs. 1 and 2. The fluctuation amplitudes were independent of frequency or amplitude of oscillation of the ring. The first measurements were made 3.1 diameters downstream of the ring. A weak turbulent wake with maximum fluctuations of about 0.2 per cent was measured at this station. Within the wake the

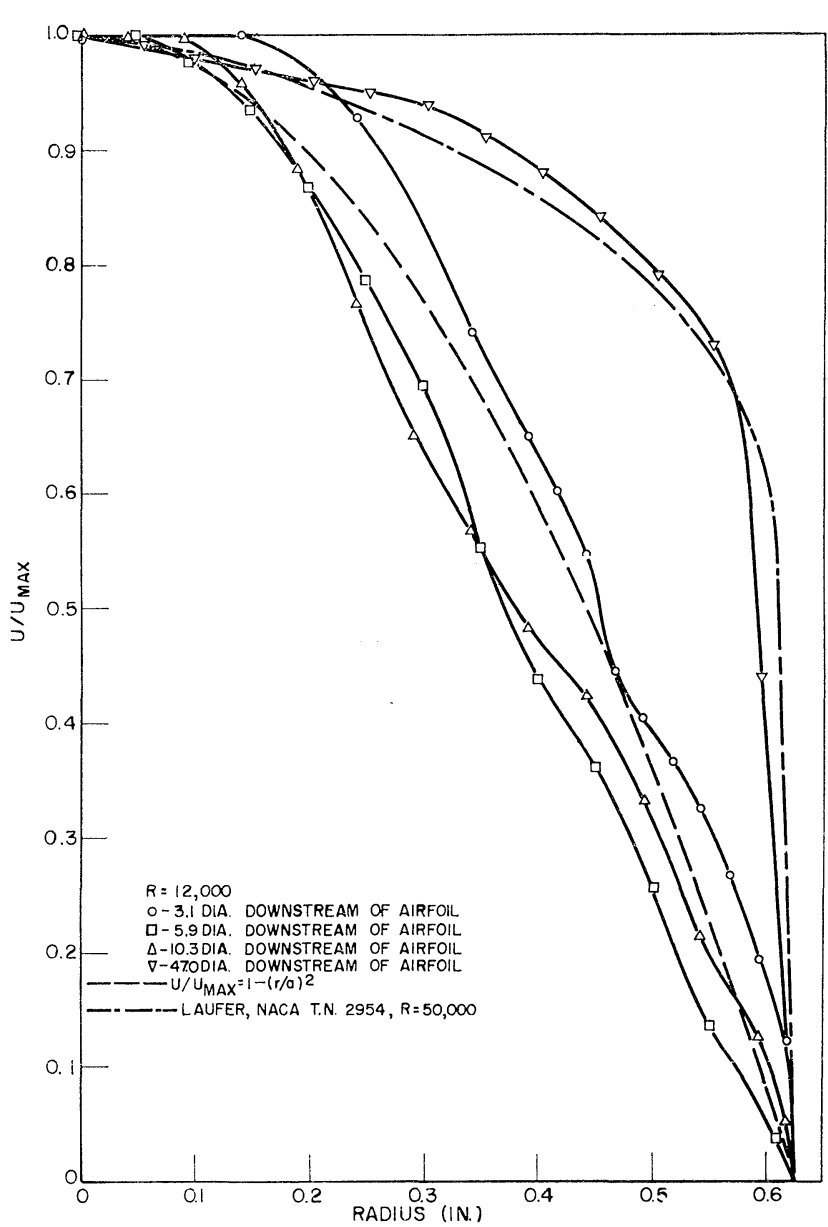

FIG. 2. Radial distribution of mean velocity downstream of ring airfoil.

fluctuations had the random character of turbulence. As we move downstream, the wake grows considerably in magnitude; however, the rate of spread is surprisingly small, the double angle being between 1.0 and 1.5 degrees. The fact that the tube flow is stable to small disturbances is probably responsible for the slow rate of spread of the wake. Between 10.3 and 47 diameters, the fluctuation profile changes radically to one very near that measured by Laufer ${ }^{59}$ in fully developed turbulent flow in a tube.

The corresponding changes in the mean velocity profiles are shown in Fig. 2. Little change is noted between 3.1 and 10.3 diameters; in fact, at 10.3 diameters, the profile is slightly farther from the turbulent distribution than it is at 3.1 diameters. The fully developed parabolic laminar profile is shown for comparison. We note that, at 47 diameters, the mean velocity profile is near that measured by Laufer. The transition distance shown by these measurements seems rather long, though intermediate measurements between 10 and 47 diameters may show rapid adjustment at some intermediate position.

As was mentioned above, the ring was stationary at a Reynolds Number of 12,000 for the results shown in Figs. 1 and 2. In fact, no change in the fluctuation amplitude could be detected when the ring was oscillated. At a Reynolds Number of 8,000 the flow was stable when the ring was stationary, but transition re- 


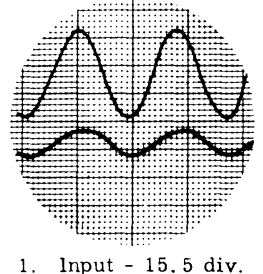

1. Input -15.5 div.

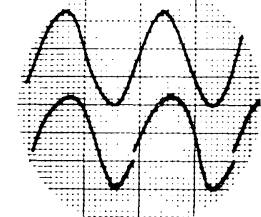

2. Input - 16.5 div. $u^{\prime} / u^{\prime} \max =0.479$

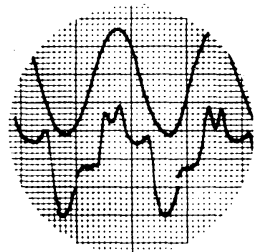

4. Input - 18.5 div. $\mathrm{u}^{\prime} / \mathrm{u}_{\max }^{\prime}=0.840$

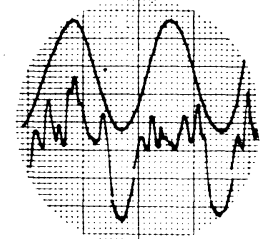

5. Input - 19.0 div. $u^{\prime} / u_{\text {max }}^{\prime}=0.622$

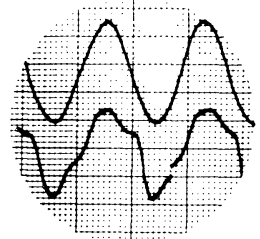

3. Input - 17.5 div. $u^{\prime} / u^{\prime} \max =1.00$

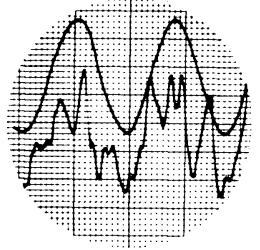

6. Input $-20.0 \mathrm{div}$. $u^{\prime} / u_{\text {max }}^{\prime}=0.537$

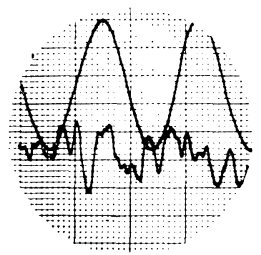

7. Input - 23.0 div. $u^{\prime} / u^{\prime} \max =0.408$

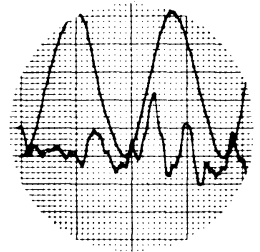

8. Input -26.0 div. $u^{\prime} / u_{\text {max }}^{\prime}=0.323$
FIG. 3. Oscillograms of velocity disturbances for various imposed disturbances with ring airfoil. Upper trace is proportional to the current input to the disturbance generator; frequency 25 cycles per sec.; Reynolds Number 4,000. Lower trace shows hot-wire response at $r / a=0.57$ (3.6 in.), 47 diameters downstream of generator. The amplification of the hot-wire response was decreased between exposures 2 and 3 .

sulted when the ring was oscillated at any frequency or amplitude. At a Reynolds Number of 4,000, it was possible to oscillate the ring in the stable or unstable regimes as shown in Fig. 3, which represents photographs of the oscilloscope traces of hot-wire response for various input signals to the disturbance generator.

In Fig. 3, the amplitude of the upper traces on each exposure is proportional to the current being supplied to the disturbance generator. The lower trace is the response of a hot wire at $r / a=0.568,47$ diameters downstream of the disturbance generator. In exposure 1 , the hot-wire response is very nearly a pure sine wave. Between exposures 1 and 2 , the current to the generator has been increased only 6.5 per cent, while the hot-wire signal increased 400 per cent. In exposure 3 , the hot-wire signal reaches a maximum $\left(u^{\prime} / u_{\max }^{\prime}=1\right)$ and the wave is visibly distorted. It is noteworthy that, in exposures 4 and 5 , the upper half of the wave is distorted much more than the lower; the velocity increases downward so that at this station, it is the low velocity half of the wave that is experiencing the maximum distortion. Characteristic turbulent fluctuations appear to have been achieved in exposures 7 and 8.

We may go a little further in describing the first stages of transition if we adopt a streamline picture similar to that found for the laminar boundary layerthat is, the disturbances in the tube would be repre- sented by ring eddies alternating in the sign of their circulation. $\dagger$ Exposures 4 and 5 indicate that initially every second disturbance eddy breaks up. More observations will be required before the essential features of the breakup of the regular disturbances can be described closely.

\section{(4) Turbulent Boundary Layer}

In the previous section, a few features of the transition from laminar to turbulent flow in boundary layers and tubes were described. While transition can come about in many ways, the final result, the turbulent boundary layer, eventually develops certain characteristics independent of the way in which the laminar flow was destroyed. Sharp, distinct boundaries separate the turbulent flow in the layer from the potential flow in the free $\operatorname{stream}^{56}$ and from the laminar flow upstream. ${ }^{53}$ The outer boundary at any particular station wanders in and out and the upstream boundary of the turbulent layer wanders upstream and downstream in a random fashion. Gaussian distribution functions describe closely the positions of both boundaries.

The mean properties of the turbulent boundary layer and the effects of roughness and compressibility have been extensively investigated by the mixing length and similarity theories. In spite of the simplifications in troduced, these theories have been remarkably successful in predicting effects of roughness and compressibility. Rather than discuss these theories, however, a more revealing approach is to consider the parameters which affect the mean velocity distribution. Many in vestigations $s^{57-63}$ have demonstrated that the turbulent layer is divided into two distinct regions; an inner region adjacent to the wall in which the distribution is in fluenced by the viscosity, and an outer region adjacent to the potential flow in which the velocity defect at any position $y / \delta$ is governed by the friction velocity $\sqrt{\tau_{0} / \rho}$. These regions are separated by an "overlapping region" in which the laws governing the flow in the inner and outer regions overlap.

The three regions are described as follows. (1) The inner or laminar sublayer region is defined as the region within which the flow phenomena are governed by the friction at the wall-i.e., by Prantl's "law of the wall" 64

$$
u^{*} \equiv U / U_{\tau}=f\left(y U_{\tau} / \nu\right) \equiv f\left(y^{*}\right)
$$

where $U$ is the mean velocity, $U_{\tau}$ is the friction velocity $\sqrt{\tau_{0} / \rho}, y$ the distance from the wall, and $\nu$ the kinematic viscosity. Hama ${ }^{65}$ gives a formula which approaches a linear relation $u^{*}=y^{*}$ for $y^{*} \rightarrow 1$ and fairs smoothly into the overlapping region described below at $y^{*}=32$. (2) The "outer region," comprising the outer

$\dagger$ Theory and experiment indicate that, for a flat plate, the disturbances may be represented by eddies, with axes normal to the flow and with circulation of alterating sign. The eddies are carried downstream at a speed less than that of the main stream. Leite's measurements ${ }^{54}$ indicate that this picture is somewhat idealized when applied to the disturbances in a tube, but qualitatively there appears to be some similarity with the configuration over a plate. 
85 per cent of the layer at low speeds, is that portion of the boundary layer in which flow conditions are independent of viscosity, but dependent on the friction at the wall. The functional dependence in this region, first recognized by von Kármán, ${ }^{66}$ is described by the functional equation

$$
\left(U_{1}-U\right) / U_{\tau}=g(y / \delta)
$$

where $U_{1}$ is the velocity at the edge of the boundary layer. This relationship describes the experiments for $y \quad U_{\tau} / \delta^{*} U_{1}>0.045$, where $\delta^{*}$ is the displacement thickness of the boundary layer. (3) The region of overlap between the inner and outer regions was shown by Millikan ${ }^{67}$ on the basis of functional reasoning, to have the semilogarithmic form. Clauser ${ }^{57}$ gives the formulas

$$
\begin{gathered}
U / U_{\tau}=5.6 \log \left(y U_{\tau} / \nu\right)+4.9 \\
\left(U_{1}-U\right) / U_{\tau}=-\left[5.6 \log \left(y U_{\tau} / \delta^{*} U_{1}\right)+0.6\right] .
\end{gathered}
$$

which then describe the velocity profile between the points $y U_{\tau} / \nu=32$ and $y U_{\pi} / \delta^{*} U_{1}=0.045$. Figs. 4 and 5 show the three regions defined by some of the experimental results.

While the three regions described above can be identified whether the turbulent flow be in a boundary layer, tube, or channel, there are important differences among the three, particularly in the outer region. $\dagger$ Deviations in the outer regions are ascribed to differences in the outer boundary condition. ${ }^{68}$ The intermittency ${ }^{56}$ of the turbulence in the outer region of the boundary layer has no counterpart in a tube or channel, since no outer potential flow exists there, and the resulting mean velocity distributions reflect this difference throughout the outer region. Over the inner region the distribution is independent of pressure gradient ${ }^{61}$ and over the outer region the distribution is independent of roughness if a small adjustment of the origin of $y$ is introduced..$^{65}$

$\dagger$ Fig. 4 shows that velocity distributions in the inner and overlap regions coincide closely for measurements in a tube (Laufer) and in a boundary layer (Kleanoff and Dieh1). Laufer's measurements in a channel60 are, however, higher than those shown, and no reason for the disagreement is evident. (See page 22 of reference 70. )

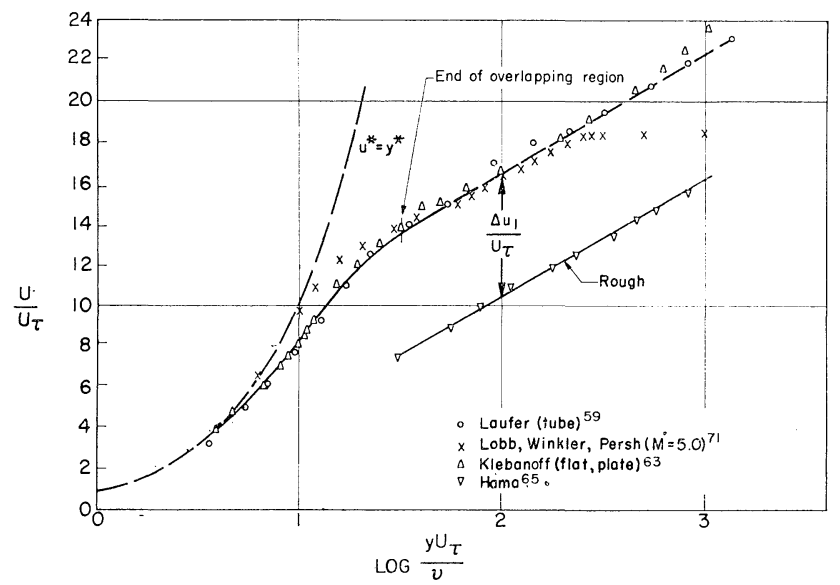

FIG. 4. Distributions of mean velocity near wall in turbulent flow. Effects of roughness and compressibility are shown. The Lobb et al data are plotted using values of $\rho$ and $\mu$ at the wall.

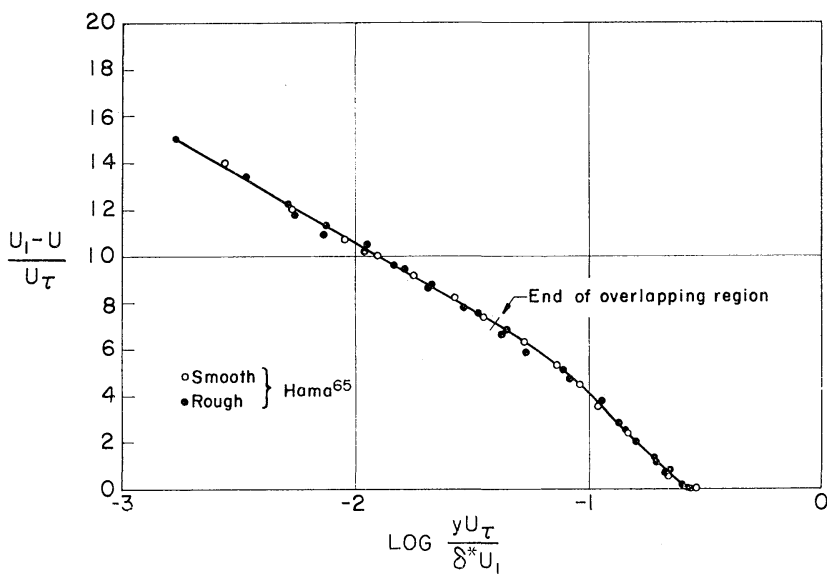

FIG. 5. Distributions of mean velocity in outer and overlapping regions of turbulent boundary layers on smooth and rough plates.

The effects of roughness are complicated by the fact that a quantitative measure of roughness depends not only on the height of the roughness element, but also on the distribution of the elements on the surface. However, as long as one deals with a particular type of roughness - e.g., sand-some interesting generalizations are possible. For instance, the influence of roughness is well represented by subtracting $\Delta u_{1} / U$ from the righthand side of Eq. (3a). ${ }^{57}$ The quantity $\Delta u_{1} / U$ is i1lustrated by some experimental results ${ }^{65}$ plotted in Fig. 4. $\Delta u_{1} / U$ is a function of $k U_{\tau} / \nu$ where $k$ is the height of the roughness elements. The results of many investigations show that the effect of roughness on the skin-friction coefficient is essentially zero if $k U_{\tau} / \nu<5$ (approx.) -i.e., if the roughness elements lie within the laminar sublayer, defined by $y U_{\tau} / \nu=y^{*} \cong 5.85$

The skin-friction coefficient law for smooth and rough plates follows from Eqs. (3a) and (3b) for the overlapping region. Adding the two equations results in the formula for local skin-friction coefficient,

$$
\sqrt{2 / c_{f}}=5.6 \log \left(U_{1} \delta^{*} / \nu\right)+4.3-\left(\Delta u_{1} / U\right)
$$

One of the important results found empirically by $\mathrm{Hama}^{65}$ is that the effect of roughness is not dependent on the outside flow and therefore the effects established for rough pipes can be applied to plates. This conclusion is true at least for "fully developed" roughness effect at zero pressure gradient.

Clauser $^{57}$ and Rotta ${ }^{69}$ analyzed the turbulent boundary layer with pressure gradient and found conditions for "similar" velocity profiles in the outer region, under the influence of pressure gradient. They found the similarity parameter

$$
G=\int_{0}^{\infty}\left(\frac{U_{1}-U}{U_{\tau}}\right)^{2} d\left(\frac{y U_{\tau}}{\delta^{*} U_{1}}\right)
$$

Clauser made extensive measurements and found $G=$ 6.1 for constant pressure and $G=10.1$ and 19.3 for two adverse pressure distributions empirically determined. The velocity profiles were similar in the sense that the above values of $G$ held over the entire length of the plate and, when the results were plotted according to Eq. (2), 


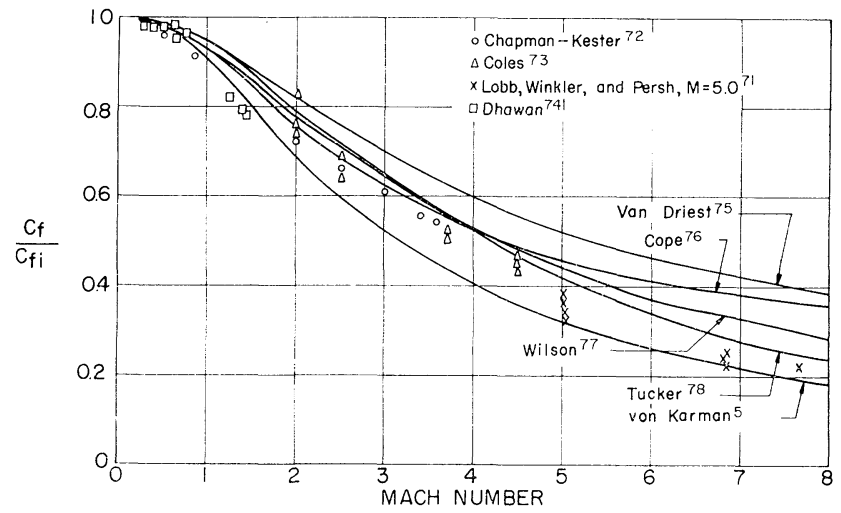

FIG. 6. Ratio of compressible to incompressible skin-friction coefficients for flat plate as function of Mach Number of externai flow.

a separate relationship $\left(U_{1}-U\right) / U_{\tau}$ vs. $y / \delta$ was defined for each pressure distribution. It was found further that the effect of pressure gradient could be represented by a $\Delta u_{2} / U_{\tau}$ analogous to the $\Delta u_{1} / U_{\tau}$ used in Eq. (4) to represent the effect of roughness. $\Delta u_{2} / U_{\tau}$ had different values for the two adverse pressure distributions for similar profiles referred to above.

A valuable review and analysis of the turbulent boundary layer in both compressible and incompressible flow was given by Coles. ${ }^{70}$ The functional reasoning leading to the various relationships for the shearing stress and for the velocity distributions in the various regions of the boundary layer is given in detail.

Some of the details of the turbulent boundary layers at high Mach Numbers are determined by Lobb, Winkler and Persh ${ }^{71}$ on the basis of total head and temperature transverses in the entrance section of a hypersonic tunnel. Free-stream Mach Numbers between 5 and 7.7 were achieved. The boundary layers were thick enough so that the measurements penetrated into the laminar sublayer. They show that, up to the highest free-stream Mach Numbers attained, the "law of the wall" $u^{*}=y^{*}$ (see Fig. 4 ) is valid, provided the properties $\mu$ and $\rho$ are evaluated at the wall.

A remarkable feature of these results is the relatively large part of the boundary layer which conforms approximately with the law of the wall. The edge of the boundary layer is at $\log y U_{\tau} / \nu=2.4$, whereas in the low-speed boundary layer this point represents less than 15 per cent of the boundary-layer thickness. Further, results taken over a wide range of values of heat transfer from the wall to the stream show that the law of the wall is valid throughout. Outside of the inner or laminar sublayer region, the velocity profile closely satisfied a power law $U / U_{1}=(y / \delta)^{1 / n}$ where $n$ decreased from 7 to 5.5 as the Mach Number increased from 5 to 7.7.

The effect of heat transfer on the skin-friction coefficient was found to be quite small. Further, calculations of the skin-friction coefficient by the use of Reynolds' analogy agreed to within 5 per cent with that given by the measured velocity gradient at the wall.

The first estimate of the effect of compressibility on the turbulent skin friction was made by von Kármán. ${ }^{5}$ He simply introduced wall properties for an insulated plate as functions of the free stream Mach Number in his formula for skin friction at low speeds, and evaluated the skin-friction coefficient as a function of the free stream Mach Number. This method receives some a posteriori justification from the results of Lobb, Winkler and Persh, ${ }^{71}$ described above, in that they find the law of the wall valid up to high Mach Numbers provided that values of density and viscosity prevailing at the wall are used in the calculation of $u^{*}$ and $y^{*}$.

In the intervening years, virtually every variation of the mixing length and similarity theories has been used to calculate turbulent skin friction at high speeds. It is not possible to distinguish between their relative accuracy except by comparison with experiment. Fortunately, there have been many excellent measurements of the skin friction on flat plates and on cone-cylinder combinations. The determinations of friction coefficients have been made by the von Kármán momentum integral, ${ }^{46}$ by overall drag measurements and by measurement of the force on a section of the plate suspended on a sensitive balance. Some of the available experimental results are plotted in Fig. 6 as the ratio of the skin-friction coefficient to that for incompressible flow vs. free-stream Mach Number. For comparison, those theoretical results which bracket the measurements are included. While there is some effect of Reynolds number on the ratio $C_{f} / C_{f_{i}}$, the major variation is with Mach Number. Fig. 6 indicates that the skin-friction coefficient on a flat plate as a function of Mach Number is slightly higher than von Kármán's estimate. A variation on von Kármán's method is given in reference 79 , along with a comparison with experiment.

Investigations of separation of turbulent boundary layers for both incompressible and compressible flow have been directed toward finding the governing dimensionless parameters. In incompressible flow, a large body of experimental data over a wide range of Reynolds Numbers indicates that the velocity profiles satisfy the functional relation ${ }^{80}$

$$
U / U_{1}=\left[f(y / \theta),\left(\delta^{*} / \theta\right)\right]
$$

where $\theta$ is the momentum thickness of the boundary layer. There is some disagreement between these measurements and the analyses of Clauser ${ }^{57}$ and Rotta ${ }^{69}$ in which the factor $G$ [Eq. (5)] rather than $\delta^{*} / \theta$ is proposed as a similarity parameter. The factors $G$ and $\delta^{*} / \theta$ are connected by the relation

$$
\delta^{*} / \theta=1 /\left(1-G \sqrt{C_{f} / 2}\right)
$$

However, Clauser found that the boundary layer was quite sensitive to small lateral pressure gradients, so that his measurements, in which precautions were taken to eliminate the lateral gradients and which showed good correlation with $G$ rather than with $\delta^{*} / \theta$, might conceivably satisfy a different similarity parameter than those of Schubauer and Klebanoif. ${ }^{80}$ Von Doenhoif and Tetervin ${ }^{81}$ give a semiempirical analysis for the growth of the turbulent layer in an adverse pressure 
gradient. Their measurements show that separation occurs for a value of $\delta^{*} / \theta$ between 2.6 and 2.8. Chapter 22 of reference 1 gives a more complete account of these and other investigations.

Separation of supersonic turbulent boundary layers has been studied by means of shock-wave interactions. In references 15 and 16 incident shocks were not strong enough to cause separation of the turbulent layer. In reference 17 , when collars with step leading edges were fitted around the body of revolution, $\Delta p / q_{1}$ for flow separation varied with $R e^{-1 / 5}$. Bogdonoff ${ }^{82}$ gives a summary of an extensive series of tests carried out at Princeton University. Optical studies and wall pressure distributions were made with incident shocks on a flat plate, with steps and with normal shocks in a diverging channel. Separation points were located with a total head tube. It was found, for instance, that separation occurred when a $10^{\circ}$ shock intersected the boundary layer at $M=2.9$ and 3.8; shocks of lesser strength did not cause separation. Reynolds Numbers based on momentum thickness of several thousand were used.

Incompressible flow about a yawed cylinder may be analyzed by the independent consideration of one of the equations of motion, provided the boundary layer is laminar (Section 2). For a turbulent layer, the fact that spanwise gradients of the velocity exist - by reason of the turbulent fluctuating velocities-nullifies the independence of the equations. However, the experimental evidence ${ }^{83,28}$ is mixed as to whether a practical degree of independence still exists. Careful investigations on yawed flat plates ${ }^{83}$ indicate that the boundarylayer properties are not the same functions of the normal distance from the leading edge as they would be if the independence principle were valid. On the other hand, measurements on yawed airfoils ${ }^{84}$ indicate approximate validity of the principle.

\section{REFERENCES}

${ }^{1}$ Schlichting, H., Boundary Layer Theory, (translation by J. Kestin); McGraw-Hill Book Company, Inc., New York, 1955.

${ }^{2}$ Howarth, L., (Ed.), Modern Developments in Fluid DynamicsHigh Speed Flow, Young, A. D., "Boundary Layers," Chapter X; Cambridge University Press, New York, 1953.

${ }^{3}$ Rubesin, M. W., Review of Recent Advanies in Knvwledge of Heat Transfer and Skin Friction in High Speed Aerodynamics, Proceedings NACA-University Conference, Vol. II, October 20-22, 1954.

${ }^{4}$ Busemann, A., Gas-Stroemung mit Laminar Grenzschicht entlang einer Platte, Z.A.M.M., Vol. 15, p. 23, 1935.

${ }^{5}$ von Kármán, Th., The Problem of Resistance in Compressible Fluids, Reale Accademia d'Italia, V Convegno della Fondazione Alessandro Volta, Roma, pp. 226-290, 1935.

${ }^{6}$ von Kármán, Th., and Tsien, H. S., Boundary Layer in Compressible Fluids, Journal of the Aeronautical Sciences, Vol. 5, No. 6, pp. 227-232, April, 1938.

${ }^{7}$ Crocco, L., Lo Strato Limite Laminare nei Gas, Monografie Scientifiche Di Aeronautica, Associazone Culturale Aeronautica, Rome, No. 3, December, 1946.

${ }^{8}$ Howarth, L., Concerning the Effect of Compressibility on Laminar Boundary Layers and Their Separation, Proc. Roy. Soc. (London), Vol. 194, pp. 16-42, 1948.
${ }^{9}$ Illingworth, C. R., Steady Flow in the Laminar Boundary Layer of a Gas, Proc. Roy. Soc. (London), Vol. 200, pp. 84-100, 1949.

${ }^{10}$ Stewartson, K., Equivalent Compressible and Incompressible Flows, Proc. Roy. Soc. (London), A, Vol. 200, pp. 84-99, 1949.

${ }^{11}$ Crocco, L., and Lees, L., A Mixing Theory for the Interaction between Dissipative Flows and Nearly Isentropic Streams, Journal of the Aeronautical Sciences, Vol. 19, No. 10, pp. 649677, October, 1952.

${ }^{12}$ Li, Ting-Yi, and Nagamatsu, H. T., Similar Solutions of Compressible Boundary-Layer Equations, Journal of the Aeronautical Sciences, Vol. 22, No. 9, pp. 607-617, September, 1955.

${ }^{13}$ Cohen, C. B., and Reshotko, E., Similar Solutions for the Compressible Laminar Boundary Layer with Heat Transfer and Pressure Gradient, NACA TN 3325, 1955.

${ }^{14}$ Levy, S., Effect of Large Temperature Changes (including Viscous Heating) upon Laminar Boundary Layers with Variable Free Stream Velocity, Journal of the Aeronautical Sciences, Vol. 21, No. 7, pp. 459-474, July, 1954.

${ }^{15}$ Ackeret, J., Feldmann, F., and Rott, N., Investigations of Compression Shocks and Boundary Layers in Gases Moving at High Speed, NACA TM 1113, 1947.

${ }^{16}$ Liepmann, H. W., Roshko, A., and Dhawan, S., On Reflec-. tions of Shock Waves from Boundary Layers, NACA Report 1100 , 1952.

${ }^{17}$ Donaldson, C. D., and Lange, R. H., Study of the Pressure Rise Across Shock Waves Required to Separate Laminar and Turbulent Boundary Layers, NACA TN 2770, 1952.

${ }^{18}$ Sears, W. R. (Ed.), "High Speed Aerodynamics and Jet Propulsion," Series; Vol. 6, General Theory of High Speed Aerodynamics; von Kármán, Th., Section A, "On the Foundation of High Speed Aerodynamics”; Princeton University Press, 1955.

${ }^{19}$ Tsien, H. S., Similarity Laws of Hypersonic Flows, Journal of Mathematics and Physics, Vol. 25, No. 3, pp. 247-251, 1946.

${ }^{20}$ Shen, S. F., An Estimate of Viscosity Effect on the Hypersonic Flow Over an Insulated Wedge, Journal of Mathematics and Physics, Vol. 31, No. 3, 1952. Also Sc.D. Thesis, Massachusetts Institute of Technology, 1949.

${ }^{21}$ Lees, L., Hypersonic Flow, paper presented at the Fifth International Aeronautical Conference, 1955, IAS preprint No. 554 .

${ }^{22}$ Moore, L. L., A Solution of the Laminar Boundary Layer Equations for a Compressible Fluid with Variable Properties, including Dissociation, Journal of the Aeronautical Sciences, Vol. 19, No. 8, pp. 505-519, August, 1952.

${ }^{23}$ Tsien, H. S., Superaerodynamics, Mechanics of Rarefied Gases, Journal of the Aeronautical Sciences, Vol. 13, No. 12, pp. 653-664, December, 1946.

${ }^{24}$ Schaaf, S. A., and Sherman, F. S., Skin Friction in Slip Flow, Journal of the Aeronautical Sciences, Vol. 21, No. 2, pp. 85-91, February, 1954

${ }^{25}$ Prandtl, L., Ueber Reibungsschichten bei Drei-Dimensionalen Stroemungen, pp. 134-141; Albert Betz Festschrift, Goettingen, Germany, 1945.

${ }^{26}$ Sears, W. R., The Boundary Layer on Yawed Cylinders, Journal of the Aeronautical Sciences, Vol. 15, No. 1, pp. 48-92, January, 1948. See also Boundary Layers in Three-Dimensional Flow (a review), Applied Mechanics Reviews, Vol, 7, No. 7, pp. 281-285, 1954.

${ }^{27}$ Jones, R. T., Effects of Sweepback on Boundary Layers and Separation, NACA Rep. 884, 1947.

${ }^{28}$ Rott, N., and Crabtree, L. F., Simplified Laminar Boundary Layer Calculations for Bodies of Revolution and for Yawed Wings. Journal of the Aeronautical Sciences, Vol. 19, No. 8, p. 553, August, 1952. See also Vol. 19, No. 12, p. 851, December, 1952, and Vol. 20, No. 1, pp. 67-68, January, 1953.

${ }^{29}$ Crabtree, L. F., The Compressible Laminar Boundary Layer on a Yawed Infinite Wing, Aeronautical Quarterly, Vol. 5, Part. 2, pp. 85-100, 1954.

${ }^{30}$ Moore, F. K., Laminar Boundary Layer on Cone in Supersonic Flow at Large Angle of Attack, NACA Rep. 1132, 1953. 
${ }^{31}$ Hayes, W., The Three-Dimensional Boundary Layer, NAVORD Report 1313, U.S. Naval Ordnance Test Station (Inyokern), 1951.

${ }^{32}$ Allen, H. J., and Perkins, E. W., A Study of Effects of Viscosity on Flow over Slender Inclined Bodies of Revolution, NACA Rep. 1048, 1951.

${ }^{33}$ Mager, A., Generalization of Boundary-Layer MomentumIntegral Systems to Three-Dimensional Flows, Including those of a Rotating System, NACA Rep. 1067, 1952. See also Journal of the Aeronautical Sciences, Vol. 21, No. 12, p. 835, 1954, NACA Rep. 1085, 1952.

${ }^{34}$ Lin, C. C., Hydrodynamic Stability, Cambridge University Press, 1955.

${ }^{35}$ Schubauer, G. B., and Skramstad, H. K., Laminar Boundary-Layer Oscillations and Transition on a Flat Plate, NACA Rep. 909, 1948.

${ }^{36}$ Probstein, R. F., and Lin, C. C., A Study of Transition to Turbulence of the Laminar Boundary Layer at Supersonic Speeds, paper presented at the Twenty-Fourth Annual Meeting, IAS, New York, 1956. IAS Preprint No. 596.

${ }^{37}$ Dryden, H. L., Review of Published Data on the Effect of Roughness on Transition from Laminar to Turbulent Flow, Journal of the Aeronautical Sciences, Vol. 20, No. 7, pp. 477-482, July, 1953.

${ }^{38}$ Gazley, Carl, Jr., Boundary-Layer Stability and Transition in Subsonic and Supersonic Flow, Journal of the Aeronautical Sciences, Vol. 20, No. 1, pp. 19-29, January, 1953.

${ }^{39}$ Lange, A. H., Giesler, L. P., and Lee, R. E., Variation of Transition Reynolds Number with Mach Number, Journal of the Aeronautical Sciences, Vol. 20, No. 10, pp. 718-719, October, 1953. See also Vol. 22, No. 4, p. 282, April, 1955.

40 Braslow, A. L., Burrows, D. L., Tetervin, N., and Visconti, F., Experimental and Theoretical Studies of Area Suction for the Control of the Laminar Boundary Layer, NACA Rep. 1025, 1951.

${ }^{41}$ Jack, J. R., and Diaconis, N. S., Variation of BoundaryLayer Transition with Heat Transfer on Two Bodies of Revolution at Mach Number 3.12, NACA TN 3562, 1955.

${ }^{42}$ Goertler, H., Ueber eine dreidimensionale Instabilitaet laminarer Grenzschichten an konkaven Waenden, Ges. d. Wiss., Goettingen, Germany, Nachr. a. d. Math., 2, No. 1, 1940.

${ }^{43}$ Smith, A. M. O., On the Growth of Taylor-Goertler Vortices along Highly Concave Walls, Quarterly Applied Mathematics, Vol. 13, No. 3, pp. 233-263, 1955.

${ }^{44}$ Liepmann, H. W., Investigation of Boundary Layer Transition on Concave Walls, NACA Wartime Rep. ACR No. 4J28, 1945.

${ }^{45}$ Gregory, N., Stuart, J. T., and Walker, W. S., On the Stability of Three Dimensional Boundary Layers with Application to the Flow due to a Rotating Disk, Philosophical Transactions of the Royal Society, London, A, Vol. 248, No. 943, pp. 155-199, 1955 .

${ }^{46}$ von Kármán, Th., Ueber Laminare und Turbulente Reibung, Zeit. f. Angew. Math. u. Mech., Vol. 1, No. 4, pp. 233-252, 1921. Translated as NACA TM 1092, 1946.

${ }^{47}$ Dunning, Robert W., and Ulmann, Edward F., Effects of Sweep and Angle of Attack on Boundary-Layer Transition on Wings at Mach Number 4.04, NACA TN 3473, 1955.

${ }^{48}$ Weske, John, and Planholt, A. H., Discrete Vortex Systems in the Transition Range of Fully Developed Flow in a Pipe, Journal of the Aeronautical Sciences, Vol. 20, No. 10, pp. 717-719, October, 1953.

${ }^{49}$ Theodorsen, Th., Mechanism of Turbulence, Proceedings, II Midwest Conference on Fluid Mechanics, Ohio State University, pp. 1-19.

${ }^{50}$ Emmons, H. W., Laminar Turbulent Transitions in a Boundary Layer, Part I, Journal of the Aeronautical Sciences, Vol. 18, No. 7, 1951. Part II, Proceedings, I National Conference for Applied Mechanics, Edwards Brothers, Ann Arbor, Mich., 1952.

${ }^{51}$ Charters, Alex C., Jr., Transition between Laminar and Turbulent Flow by Transverse Contamination, NACA TN 891, 1943.
${ }^{52}$ Evvard, John C., Tucker, Maurice and Burgess, Warren, C., Jr., Transition-Point Fluctuations in Supersonic Flow, Journal of the Aeronautical Sciences, Vol. 21, No. 11, pp. 731-738, November, 1954.

${ }^{53}$ Schubauer, G. B., and Klebanoff, P. S., Contributions on the Mechanics of Boundary-Layer Transition, NACA TN 3489, 1955.

${ }^{54}$ Leite, R. J., An Experimental Investigation of the Stability of Axially Symmetric Poiseuille Flow, Ph.D. Dissertation, University of Michigan, Ann Arbor, 1956. OSR-TR-56-2, Final Report on Contract AF 18(600)-350.

${ }^{55}$ Corcos, G. M., and Sellars, J. R., On the Stability of Fully Developed Flow in a Pipe, (to be published).

${ }^{56}$ Corrsin, Stanley, and Kistler, Alan L., The Free Stream Boundaries of Turbulent Flows, NACA TN 3133, 1955.

${ }^{57}$ Clauser, Francis, Turbulent Boundary Layers in Adverse Pressure Gradients, Journal of the Aeronautical Sciences, Vol. 21, No. 2, pp. 91-108, February, 1954. Also Advances in Applied Mechanics, Th. von Kármán, (Ed.), Vol. IV, Academic Press, New York, 1956.

${ }^{58}$ Schultz-Grunow, F., New Frictional Resistance Law for Smooth Plates, NACA TM 986, 1941.

${ }^{59}$ Laufer, John, The Structure of Turbulence in Fully Developed Pipe Flow, NACA TN 2954, 1953.

${ }^{60}$ Laufer, John, Investigation of Turbulent Flow in a Two-Dimensional Channel, NACA Rep. 1953, 1951.

${ }^{61}$ Ludwieg, H., and Tillman, W., Investigations of the Wall Shearing Stress in Turbulent Boundary Layers, NACA TM 1285, 1950.

${ }^{62}$ Ross, Donald, A New Analysis of Nikuradse's Experiments on Turbulent Flow in Smooth Pipes, Proceedings III Midwest Conference on Fluid Mechanics, University of Minnesota, pp. 651-659, 1953

${ }^{63}$ Klebanoff, P. S., and Diehl, Z. W., Some Features of Artificially Thickened Fully Developed Turbulent Boundary-Layers with Zero Pressure Gradient, NACA Rep. 1110, 1952.

${ }^{64}$ Durand, W. F., (Ed.), Aerodynamic Theory, Prandtl, L., "The Mechanics of Viscous Fluids," Article G, Vol. 3, Durand Reprinting Committee, Pasadena.

${ }^{65}$ Hama, Francis, Boundary Layer Characteristics for Smooth and Rough Surfaces, Transactions Society of Naval Architecture and Marine Engineering, Vol. 62, pp. 333-358, 1954.

${ }^{66}$ von Kármán, Th., Mechanicshe Aehnlichkeit und Turbulenz, Proceedings III International Congress of Applied Mechanics, Stockholm, p. 83, 1930. NACA TM 611, 1931.

${ }^{67}$ Millikan, C. B., A Critical Discussion of Turbulent Flows in Channels and Tubes, Proceedings V International Congress for Applied Mechanics, Cambridge, Massachusetts pp. 386-392, 1938.

${ }^{68}$ Schubauer, G. B., Turbulent Processes as Observed in Boundary Layer and Pipe, Journal of Applied Physics, Vol. 25, No. 2, pp. 188-196, 1954.

${ }^{69}$ Rotta, J., On the Theory of Turbulent Boundary Layers, NACA TM 1344. See also Ingenieur Archiv Vol. 18, p. 270, 1950, and Vol. 19, p. 31, 1951. Similar Solutions of Turbulent Boundary Layers, Journal of the Aeronautical Sciences, Vol. 22, No. 3, pp. 215-216, March, 1955.

${ }^{70}$ Coles, Donald, Measurements in the Boundary Layer on a Smooth Flat Plate in Supersonic Flow, I. The Problem of the Turbulent Boundary Layer, Rep. No. 20-69, Jet Propulsion Laboratory, California Institute of Technology, Pasadena, 1953.

${ }^{71}$ Lobb, R. Kenneth, Winkler, Eva M., and Persh, Jerome, Experimental Investigation of Turbulent Boundary Layers at Hypersonic Speeds, Journal of the Aeronautical Sciences, Vol. 22, No. 1, pp. 1-10, January, 1955.

${ }^{72}$ Chapman, Dean R., and Kester, Robert H., Measurements of Turbulent Skin Frictions on Cylinders in Axial Flow at Subsonic and Supersonic Velocities, Journal of the Aeronautical Sciences, Vol. 20, No. 7, pp. 441-449, July, 1953.

${ }^{73}$ Coles, Donald, Measurements in the Boundary Layer on a Smooth Flat Plate in Supersonic Flow, III Rep. No. 20-71, Jet Propulsion Laboratory, California Institute of Technology, 
${ }^{17}$ Ilyushkin, A. A., The Elasto-Plastic Stability of Plates, Translation in NACA Tech. Memo. No. 1188, 1947.

${ }^{18}$ Gerard, G., Secant Modulus Method for Determining Plate Instability Above the Proportional Limit, Journal of the Aeronautical Sciences, Vol. 13, No. 1, pp. 38-44, January, 1946.

${ }^{19}$ Stowell, E. Z., A Unified Theory of Plastic Buckling of Columns and Plates, NACA Tech. Note No. 1556, 1948.

${ }^{20}$ Handelman, G. H. and Prager, W., Plastic Buckling of a Rectangular Plate under Edge Thrusts, NACA Tech. Note No. 1530, 1948.

${ }^{21}$ Pride, R. A. and Heimerl, G. J., Plastic Buckling of Simply Supported Compressed Plates, NACA Tech. Note No. 1817, 1949.

${ }^{22}$ Onat, E. T. and Drucker, D. C., Inelastic Stability and Incremental Theories of Plasticity, Journal of the Aeronautical Sciences, Vol. 20, No. 3, pp. 181-186, March, 1953.

${ }^{23}$ Krivetsky, A., Plasticity Coefficients for the Plastic Buckling of Plates and Shells, Journal of the Aeronautical Sciences, Vol. 22, No. 6, pp. 432-435, June, 1955.

${ }^{24}$ Koiter, W. T., The Effective Width of Infinitely Long Flat Rectangular Plates under Various Conditions of Edge Restraint, National Luchtvaartlaboratorium, Amsterdam, Rep. No. S-287, 1943.

${ }^{25}$ Botman, M., and Besselring, J. F., The Effective Width in the Plastic Range of Flat Plates under Compression, N.L.L., Amsterdam, Rep. No. S-445, 1954.

${ }^{26}$ Stowell, E. Z., Critical Shear Stress of an Infinitely Long Plate in the Plastic Region, NACA Tech. Note No. 1681, $194^{?}$.

${ }^{27}$ Gerard, G., Critical Shear Stress of Plates Above the Proportional Limit, Journal of the Aeronautical Sciences, Vol. 15, No. 1, pp. 53-56, Janua-y, 1948.

${ }^{28}$ Stowell, E. Z., and Pride, R. A., Plastic Buckling of Extrudel Composite Sections in Compression, NACA Tech. Note No. 1971, 1949.

${ }^{29}$ Needham, R. A., The Ultimate Strength of Aluminum Alloy Formed Structural Shapes in Compression, Journal of the Aeronautical Sciences, Vol. 21, No. 4, pp. 217-229, April, 1954.
${ }^{30}$ Wittrick, W. H., Latsral Instability of Rectangular Beams of Strain-Hardening Material under Uniform Bending, Journal of the Aeronautical Sciences, Vol. 19, No. 12, pp. 835-843, December, 1952.

${ }^{31}$ Bijlaard, P. P., Analysis of the Elastic and Plastic Stability of Sandwich Plates by the Method of Split Rigidities, Part I, Journal of the Aeronautical Sciences, Vol. 18, No. 5, pp. 339-349, May, 1951; Part II, Journal of the Aeronautical Sciences, Vol. 18, No. 12, pp. 790-796, December, 1951.

${ }^{32}$ Klein, B., Rapid Estimation of the Elastic-Plastic Euler Buckling Loads for Simply Supported Tapered Columns under Varying Axial Loading, Journal of the Aeronautical Sciences, Vol. 22, No. 12, pp. 873-874, December, 1955.

${ }^{33}$ Hoff, N. J., Rapid Creep in Structures, Journal of the Aeronautical Sciences, Vol. 22, No. 10, pp. 661-672, October, 1955.

${ }^{34}$ Kempner, J., Creep Bending and Buckling of Linearly Viscoelastic Columns, NACA Tech. Note No. 3136, 1954.

${ }^{35}$ Kempner, J., Creep Bending and Buckling of Nonlinearly Viscoelastic Columns, NACA Tech. Note No. 3137, 1954.

${ }^{36}$ Libove, C., Creep Buckling of Columns, Journal of the Aeronautical Sciences, Vol. 19, No. 7, pp. 459-467, July, 1952.

${ }^{37}$ Libove, C., Creep Buckling Analysis of Rectangular Section Columns, NACA Tech. Note No. 2956, 1953.

${ }^{38}$ Higgins, T. P., Jr., Effect of Creep on Column Deflection, Inst. Aero. Sci., Preprint No. 385, 1952. See also, WeightStrength Analysis of Aircraft Structures, Chapter 20; Shanley, F. R., McGraw-Hill Book Co., 1952.

${ }^{39}$ Patel, S. A., Bloom, M., Erickson, B., Chwick, A. and Hoff, N. J., Development of Equipment and of Experimental Techniques for Column Creep Tests, NACA Tech. Note No. 3493, 1955.

${ }^{40}$ Kempner, J. and Patel, S. A., Creep Buckling of Columns, NACA Tech. Note No. 3138, 1954.

${ }^{41}$ Baer, H. W., Very Short Time Creep Buckling, Hughes Aircraft Co., Tech. Memo. No. 306, 1953.

\title{
Some Features of Boundary Layers . . .
}

\author{
(Continued from page 452)
}

1953. See also Journal of the Aeronautical Sciences, Yol. 21, No. 7, pp. 433-449, July, 1954.

${ }^{74}$ Dhawan, Satish, Direct Measurements of Skin Friction, NACA TN 2567, 1952.

${ }^{75}$ Van Driest, Turbulent Bolindary Layer in Compressible Fluids, Journal of the Aeronautical Sciences, Vol. 18, No. 3, pp. 145-160, March, 1951.

${ }^{76}$ Cope, W. F., The Turbulent Boundary Layer in Compressible Flow, NPL Eng. Dept. British ARC 7634, 1943.

77 Wilson, Robert E., Turbulent Boundary Layer Characteristics at Supersonic Speeds--Theory and Experiment, Journal of the Aeronautical Sciences, Vol. 17, No. 9, pp. 585-594, September 1950.

${ }^{78}$ Tucker, Maurice, Approximate Calculation of Turbulent Boundary Layer Development in Compressible Flow, NACA TN 2337, 1951.

${ }^{79}$ Rubesin, M. W., Maydew, R. C., and Varga, S. A., $A n$ Analytical and Experimental Investigation of Skin Friction of Turbulent Boundary Layer on Flat Plate at Supersonic Speeds, NACA TN 2305, 1951.
${ }^{80}$ Schubauer, G. B., and Klebanoff, P. S., Investigation of Separation of Turbulent Boundary Layer, NACA Rep. 1030, 1951.

${ }^{81}$ von Doenhoff, A. E., and Tetervin, N., Determination of General Relations for the Behavior of Turbulent Boundary Layers, NACA Rep. 772, 1943.

${ }^{82}$ Bogdonoff, Seymour M., Some Experimental Studies of the Separation of Supersonic Turbulent Boundary Layers, Fluid Mechanics and Heat Transfer Institute, University of California, Los Angeles, 1955.

${ }^{83}$ Ashkenas, H. L., and Riddell, F. R., Investigation of the Turbulent Boundary Layer on a Yawed Flat Plate, NACA TN 3383, 1955.

${ }^{84}$ Altman, J. M., and Hayter, N. L. F., A Comparison of the Turbulent Boundary Layer Growth on an Unswept and a Swept Wing, NACA TN 2500, 1951.

${ }^{85}$ von Kármán, Th., Turbulent Skin Friction, Journal of the Aeronautical Sciences, Vol. 1, No. 1, pp. 1-20. January, 1934. 